\title{
A imprensa em Mato Grosso: subsídios para o ensino da História Regional no século XIX (1880-1890)1
}

\author{
Mato Grosso in the press: grants for education in \\ Regional History in the nineteenth century (1880-1890)
}

Adriana Aparecida Pinto*

\section{RESUMo}

O ensino de história conta com um conjunto de aportes teóricos que discutem teorias e estratégias de ensino, bem como auxiliam na reflexão sobre os modos de fazer e proceder com os conteúdos em sala de aula. Nessa direção, o presente artigo insere-se nas preocupações da História a ser ensinada, com enfoque nas discussões da história regional, utilizando para isso, fontes ligadas à imprensa periódica de circulação geral. Apresentam-se, aqui, possibilidades interpretativas para o uso dessa tipologia documental, com enfoque no ensino da história de Mato Grosso no período de transição do regime imperial para o republicano. Por meio da imprensa, evidenciam-se debates, disputas por poder, bem como um conjunto de práticas educativas que dão a conhecer a alunos e professores os contextos históricos que não são necessariamente contemplados em fontes oficiais ou de outras naturezas.

Palavras-chave: ensino de história regional; imprensa periódica; Mato Grosso.

\section{Abstract}

The teaching of history has a set of theoretical contributions that discuss theories and teaching strategies as well as help to understand the ways of doing and proceeding with the contents in the classroom. In this direction, this paper inserts on the concerns of history to be taught, focusing on discussions of regional history, using for this, sources close to the periodical press of general circulation. Are presented here, interpretive possibilities for the use of this document typology, focusing on the teaching of the history of Mato Grosso in the transition period of the imperial regime for the Republican. Through the press, show up debates, disputes over power, as well as a set of educational practices that give recognition to students and teachers, historical contexts that are not necessarily included in official or other nature sources.

Keywords: regional history teaching; periodical press; Mato Grosso (Brazil).

\footnotetext{
* Universidade Federal da Grande Dourados (UFGD). adrianapintoufgd@gmail.com
} 
Finais de século são bons para pensar.

Costa; Schwarcz; Melo e Souza, 2000

As décadas finais do século XIX em Mato Grosso² foram marcadas por conflitos e indecisões que assolavam não apenas o território mato-grossense, mas o país como um todo. Nessa seara, os debates em relação à improbidade e ineficiência do regime imperial visando à implantação do regime republicano foram acirrados, estabelecendo posições e oposições, redesenhando o contorno e a história das Províncias. Tais disputas e debates refletiram nos conhecimentos históricos a serem ensinados ao delimitar e/ou determinar um conjunto de referências e "acontecimentos" históricos a serem abordados, temas sobre os quais "contar" ou não, reiterando posicionamentos políticos de grupos familiares que se alternavam no poder. ${ }^{3}$

No entanto, temas inerentes a essa movimentação sociopolítica e outras temáticas derivadas desse contexto não são, comumente, conteúdos do ensino de história de Mato Grosso, a qual carece, a nosso ver, de discussão e investimento significativo por parte dos profissionais do ensino e da pesquisa em História, tendo em vista serem conteúdos que não figuram com regularidade no material de ensino comumente utilizado por professores, sobretudo nos livros didáticos. ${ }^{4}$

Essas ausências intensificam-se com a falta de material didático produzido e disponibilizado para esse fim e, ainda, com a precária divulgação e circulação de trabalhos acadêmicos sobre estudos dessa natureza entre professores da rede pública de ensino. Cabe ainda uma ressalva acerca da resistência em se abordar o tema: a dificuldade em se encontrar fontes locais, ou mesmo o trabalho de garimpar essas fontes, que demandam formação adequada do professor para a pesquisa, aliada a falta de tempo e condições de deslocamentos necessário (Ribeiro et al., 2013).

Em relação aos títulos que estão à disposição dos professores para auxiliar no ensino da história regional, no ensino fundamental, anos iniciais, Laura Maciel faz algumas ressalvas:

Em geral, essas obras didáticas abordam a constituição histórica de uma porção do território nacional, e apresentam uma narrativa sobre o local ou região conduzida pelas etapas de "formação" do território da nação, ou pela "ocupação huma- 
na" de uma porção do território, silenciando ou minimizando a violência, os conflitos e diferentes temporalidades que marcaram o processo de "integração nacional". Segundo avaliações dos próprios avaliadores/autores do Guia de Livros Didáticos, em sua versão 2010, algumas obras regionais organizam os conteúdos "em ordem cronológica de acontecimentos sobre um estado da federação, ou município, seguindo a periodização político-administrativa em relação à História do Brasil" (MEC, 2009, p.16-17). Ou seja, é a história institucional e política do país que orienta e pauta a seleção de momentos e experiências locais considerados historicamente relevantes para os diversos autores.

Logo, nem sempre as obras didáticas regionais - produzidas conforme a lógica [ou "tradição editorial"] do mercado editorial e do processo de regionalização dos currículos - se constituem como instrumentos para a reflexão crítica sobre especificidades socioculturais, que diferenciam e aproximam os brasileiros em diferentes territórios, nem tampouco contribuem para problematizar as ênfases, momentos e personagens consagrados na história do Brasil em sua versão tradicional. (Maciel, 2013, p.85)

Não obstante, a mesma autora, ao analisar alguns títulos, constata que nem sempre essas obras fogem ao apelo de uma história factual, baseada em aspectos políticos e econômicos:

Poucos autores se propõem a oferecer elementos que permitam a professores/ alunos refletir sobre as diversidades regionais locais ou sobre as muitas vozes expropriadas e silenciadas - mulheres, afrodescendentes, indígenas -, numa narrativa oficial da história regional, orientações expressas nos editais do Plano Nacional de Livro Didático, em suas versões mais recentes (PNLD, 2013, p.25). É grande, portanto, o risco de que a história ensinada sirva ao reforço de especificidades geográfico-territoriais, ou de características culturais, étnicas e sociais hegemônicas, e supostamente harmônicas, reforçando ideologias identitárias que servem de base aos preconceitos e xenofobia. (Maciel, 2013, p.85)

Ao identificar possibilidades de escrita e ensino de uma história regional, não se pretende hierarquizar regiões, pois entendemos que o regional não se sobrepõe ao nacional, mas sim, elucidar aspectos para a compreensão das formas e manifestações da sociedade, naquele espaço e em relação ao tempo em que ocorreram, insertas em um cenário mais amplo, o nacional. ${ }^{5}$ 
Com base nesse argumento e em opções limitadas de materiais que auxiliem o ensino dos aspectos históricos regionais (didáticos e paradidáticos), ${ }^{6}$ cuja produção é tarefa considerada importante, a ser realizada por historiadores do Estado, conforme assinala Paulo Roberto Cimó Queiroz (Leite, 2010) para a instrumentalização do ensino de história de Mato Grosso e Mato Grosso do Sul, ${ }^{7}$ entendemos que o ensino de história regional pode ser potencializado a partir do uso de fontes ligadas à imprensa periódica educacional, tendo em vista que retratam, ainda que com um viés pontual, momentos, situações, disputas e embates ocorridos no período em que circularam.

Partimos do pressuposto de que o ensino de história regional contribui para a construção de uma identidade local, inserida no cenário nacional, ${ }^{8}$ contudo, tem o objetivo de reforçar o conhecimento da região em que se refere, dando a conhecer processos e percursos históricos, contribuindo para o sentimento de identidade regional e pertencimento à comunidade local (Zorzato, 2000). Em face do exposto, o presente artigo busca evidenciar aproximações entre as possibilidades de ensino de história regional no tocante aos anos finais do período imperial, relacionadas à imprensa periódica de circulação geral (jornais) que circularam em Mato Grosso entre os anos de 1880 e 1890.

\section{HisTóRIA REGIONAL, ENSINO E IMPRENSA: DIÁLOGOS PRODUTIVOS ${ }^{9}$}

O ensino de história vem sendo objeto de interesse da comunidade acadêmica de modo mais intensivo desde a década de 1990, com o trabalho inaugural de Circe Bittencourt, Livro didático e conhecimento histórico: uma história do saber escolar, cujos desdobramentos são observados até nossos dias, fruto dos esforços de pesquisadores que se debruçaram sobre a compreensão de várias dimensões do ensino de história (Monteiro et al., 2007; Giacomoni; Pereira, 2013; Bittencourt, 2004; Silva; Zamboni, 2013; RIBEIRO et al., 2013). Recentemente destacaram-se estudos que buscam entender as dimensões da aprendizagem histórica no diálogo com a produção do historiador e filósofo alemão Jörn Rüsen (Schmidt, 2011; Fronza, 2012). As discussões sobre o tema contam com significativa produção de pesquisas que versam sobre as mais variadas e distintas abordagens, sendo reiteradas na divulgação das pesquisas e produção da área, que já se encontra consolidada no âmbito dos cursos de História e Educação. ${ }^{10}$ 
Ainda assim, vale retomar, na perspectiva de Ana Maria Monteiro, a relevância dessa área de conhecimento, tendo em vista ser um campo disciplinar que envolve múltiplos saberes:

a história é uma disciplina escolar que tem (ou deveria ter) profunda relação com a prática sociopolítica e cultural, mas que muitas vezes se torna um conhecimento esotérico e enigmático para os alunos, fenômeno este que acreditamos estar de alguma forma relacionado com a ação dos professores ... Além disso, a História é uma disciplina que, como as outras, passou por mudanças de paradigmas ao longo do século XX, com profundas repercussões nos processos de pesquisa e elaboração científica ... Reconhecemos, também, em grande número de professores de História, um compromisso afirmado e vivenciado com o desenvolvimento de um ensino para formar cidadãos críticos, mas são professores frustrados com a falta de adesão dos alunos à militância proposta. (Monteiro, 2007, p.27)

A responsabilidade da formação social e política atribuída ao ensino de história e, consequentemente, aos professores que ministram a disciplina, não encontra respaldo na organização da estrutura de ensino brasileiro, como componente curricular, visto que a cada reforma de ensino, essa e outras disciplinas relativas às humanidades vêm perdendo espaço, com a diminuição de sua carga horária efetiva de ensino em sala de aula. Não obstante, muitas dessas reflexões nem sempre conquistam a adesão dos profissionais que estão, efetivamente, à frente do seu ensino, criando um hiato entre o que se produz, com base em pesquisas e estudos acadêmicos, e o que se verifica no cotidiano das práticas escolares.

Para minimizar o hiato entre a formação dos professores nos cursos de licenciatura e sua atuação nas instituições de ensino regular, aliam-se investimentos potenciais em Laboratórios de Ensino de História em Universidades Públicas no país, muitos dos quais com produção de material bibliográfico e periódicos que versam sobre as relações entre ensino e aprendizagem histórica. A título de exemplo citam-se as iniciativas em andamento: UFGRS (LHISTE), UFMG (LABEPHE), FGV (LEH) e UFU (LEAH), LAPEDUH (UFPR), UDESC (LEH) e UEL (Laboratório de Ensino de História).

O profissional de História lida com experiências humanas coletivas ou individuais, independentemente da distância temporal em relação ao presente. A capacidade de leitura, escrita e socialização do conhecimento que perfaz o ensino 
e a pesquisa em História requer capacidade de intelecção compreendida pela noção de imaginação histórica, procedimentos necessários para a construção de representações que constituem, em primeira instância, um campo de interpretação baseado em condições verossímeis do passado. Nesse sentido, a compreensão da dimensão histórica regional é entendida como conhecimento significativo para a composição do conjunto de referências a serem ensinadas na escola. A importância dessa discussão é evidenciada por Marcos Lobato Martins:

História Regional é aquela que toma o espaço como terreno de estudo, que enxerga as dinâmicas históricas no espaço e através do espaço, obrigando o historiador a lidar com processos de diferenciação de áreas. A História Regional é [aquela em] que você vê o lugar, a região e o território como natureza da sociedade e da história, e não apenas como palco imóvel onde a vida acontece. Ela é História Econômica, Social, Demográfica, Cultural, Política etc., referida ao conceito chave de região. (Martins, 2009, p.143)

Por ausência de estudos ou interesse na área, esse autor destaca a iniciativa de pesquisadores paulistas em escrever e entender a sua história, na perspectiva da região, iniciativa a qual considera responsável por uma espécie de transposição da história paulista para a história nacional, afirmando que "a hegemonia econômica e acadêmica de São Paulo possibilitou a identificação de sua história com a história do Brasil, mais recente" (Martins, 2009, p.141-142).

Nos debates em direção à consolidação de espaços de discussão e acerca do seu ensino, Ana Maria Monteiro destaca que o campo de pesquisa em ensino de história encontra-se em constituição, resultando do esforço e trabalhos de pesquisadores e professores, em espaço interdisciplinar que congrega interesses das áreas da Educação e História, interessados em compreender as implicações sociais, políticas e culturais presentes no ensino de história (Monteiro, 2007, p.7).

A Editora Base investiu significativamente na produção de livros didáticos que abordem as questões regionais de todos os estados brasileiros. ${ }^{11}$ No entanto, essa produção ainda demanda investimentos potenciais de análise e pesquisas, pois alguns títulos, como o analisado por Laura Maciel (2013), não contemplam questões essenciais para a constituição dos saberes históricos:

Para isso, o ensino de história regional deveria ser orientado pelo reconhecimento de processos históricos socialmente compartilhados - sem, no entanto, silen- 
ciar sobre alternativas e possibilidades históricas em cada conjuntura analisada e nem perder de vista as articulações mais amplas -, assim como pela evidenciação de aproximações culturais e linguísticas, mas atentos às diferenças e contraposições de outras culturas que também fazem parte da região. (Maciel, 2013, p.86)

Em termos de teoria historiográfica, Jacques Le Goff aponta uma nova perspectiva de compreender a multiplicidade contida no conceito de documento, extrapolando os limites impostos pelos escritos, bem como a possibilidade de estabelecer articulações entre a história regional e a local, "que revelou por estudos eruditos e precisos a presença do poder onde a história tradicional sequer pensava em procurá-la (no simbólico e no imaginário, por exemplo), vê-se quase condenada, eu diria, por sua problemática ser transparente nesse domínio" (Le Goff, 2005, p.5). Esse campo de interpretação, na proposta deste artigo, tem na imprensa periódica espaço privilegiado para compreensão de temporalidades, comportamentos sociais, ao lado de outros elementos da cultura social e escrita. A imprensa configura-se como registro de testemunhos escritos, que evidenciam determinados modos de compreender os acontecimentos locais em meio a disputas sociais por espaço, opinião, interesses econômicos, morais e políticos dentre outros aspectos.

Marco Morel (2008) afirma que a imprensa não surge, no Brasil, como uma forma de distração e espaço de opiniões vagas e simplórias, e sim, “em meio a uma densa trama de relações e formas de transmissão, já existentes, na qual a imprensa se inseria" (Morel, 2008, p.25). Na visão desse autor, “o periodismo pretendia, também, marcar e ordenar uma cena pública que passava por transformações nas relações de poder que diziam respeito a amplos setores da hierarquia da sociedade, em suas dimensões políticas e sociais (ibidem, p.25).

Ao fazer circular notícias sobre o modo de vida político e social, a imprensa intenciona produzir, em certa medida, um efeito modelar, tornando públicos e aceitáveis comportamentos que se assemelharem ao posto em circulação, gerando novos ordenamentos, ou seja, "marcava e era marcada por vozes, gestos e palavras" (ibidem, p.26).

Publicar um jornal em meados do século XIX, embora fosse oneroso, visto que demandava equipamento específico e caro, não era tão difícil assim:

Mesmo demandando alguns recursos financeiros, não era preciso ser muito rico para fazer circular um jornal, que tinha formato pequeno e poucas páginas, com 
anúncios escassos. Tanto um jornal governista quanto um oposicionista tinham um alcance, em princípio, semelhante. E não era necessário ser um privilegiado social para comprar eventualmente um exemplar, cujo preço estava acessível até mesmo para um escravo de ganho que se interessasse em sua leitura. (Morel, 2008, p.36)

Os jornais faziam circular as produções livrescas, visto que eram publicados no formato de fascículos ou capítulos, seguindo a sequência dos exemplares publicados semanalmente. A imprensa periódica fornece indicativos para a compreensão de questões históricas que não estão dadas, a priori, no material de uso comum de alunos e professores. A proposta de trabalho com essa tipologia documental demanda esforço de organização, tendo em vista a seleção de títulos, localização, mapeamento dos números e exemplares existentes, ao lado da viabilidade e condições de acesso e manuseio, dadas pelo formato digital, por meio de exemplares microfilmados, ou ainda por meio da consulta efetiva à fonte, que requer cuidados extremos, sobretudo quando se trata de exemplares de tempos mais recuados, em virtude da própria característica de produção e condição de conservação do material.

Os estudos realizados por Maria Alice Faria enunciaram em termos históricos e didáticos a potencialidade do ensino de história oportunizada através do uso de jornais, destacando que

o jornal é também uma fonte primária de informação, espelha muitos valores, e se torna um instrumento importante para o leitor se situar e se inserir na vida social e profissional ... ele leva o aluno a conhecer diferentes posturas ideológicas frente a um fato, a tomar posições fundamentadas e aprender a respeitar diferentes pontos de vista... (Faria, 2003, p.11)

A pesquisa e o uso de documentos de períodos mais recuados carecem de adeptos no contexto escolar, por uma série de motivos: dificuldade do acesso aos acervos de guarda e preservação de fontes (arquivos públicos, museus, centros de documentação e de memória, dentre outros), organização da estrutura didática que nem sempre permite mobilidade de datas e horários para a prática extramuros da escola, formação dos professores que dificulta a leitura de fontes de natureza diversa àquela apresentada no livro didático e o preparo de aulas cujo enfoque esteja centrado não apenas no material didático regularmente utilizado para esse fim; dificuldades de locomoção e acesso dos alunos aos locais 
de memória e guarda documental, aliada à responsabilidade em deslocar crianças e adolescentes para espaços públicos sem criar situações nas quais escola e professores responsáveis tenham problemas futuros, dentre outras.

Atualmente, com a disponibilização dos acervos físicos de Bibliotecas e Acervos, na modalidade virtual, via digitalização da documentação, ao lado do fomento ao uso das tecnologias ligadas à informação, bem como a popularização ao acesso à internet e às "novas tecnologias", recursos podem ser potencializados em favor das aulas de História, não substituindo o exercício, prazer e necessidade de se conhecer lugares e as condições de guarda e arquivamento documental, no entanto abreviam e aproximam o contato do aluno com temporalidades distintas àquela em que estão inseridos, por meio de material produzido no período selecionado para estudo.

NotAS MATO-GROSSENSES: JORNAIS E ENSINO DA HISTÓRIA

O final do século XIX, em Mato Grosso, na perspectiva e análise de Virgílio Correa Filho, configura-se como fecundo no que se refere ao desenvolvimento e visibilidade nacional do território mato-grossense. É possível, com base nos dados apresentados por esse autor, conhecer as localidades existentes, ao lado de seu quantitativo populacional:

Tabela 1 - Síntese da população mato-grossense em 1880

\begin{tabular}{|c|c|c|c|c|c|}
\hline Municípios & Freguesias & Homens & Mulheres & Total & Escravos \\
\hline \multirow{7}{*}{ Cuiabá } & $\begin{array}{c}\text { Senhor Bom Jesus } \\
\text { de Cuiabá }\end{array}$ & 6.301 & 4.901 & 11.201 & * \\
\hline & São Gonçalo de Pedro II & 2.987 & 2.661 & 5.648 & * \\
\hline & Nossa Senhora da Guia & 1.386 & 1.487 & 2.873 & * \\
\hline & $\begin{array}{l}\text { Nossa Senhora } \\
\text { do Livramento }\end{array}$ & 2.130 & 2.092 & 4.229 & 3.759 \\
\hline & $\begin{array}{l}\text { Santo Antonio } \\
\text { do Rio Abaixo }\end{array}$ & 3.076 & 2.397 & 5.073 & * \\
\hline & $\begin{array}{c}\text { S. Anna do Sacramento } \\
\text { da Chapada }\end{array}$ & 1.092 & 1.073 & 2.165 & * \\
\hline & Nossa Senhora de Brotas & 2.789 & 3.032 & 5.821 & * \\
\hline
\end{tabular}

continua na página 352 


\begin{tabular}{|c|c|c|c|c|c|}
\hline Miranda & $\begin{array}{c}\text { N. Senhora do Carmo } \\
\text { de Miranda }\end{array}$ & 2.110 & 2.113 & 4.223 & * \\
\hline \multirow{2}{*}{ Corumbá } & Santa Cruz de Corumbá & 1.949 & 1.633 & 3.582 & 136 \\
\hline & $\begin{array}{l}\text { S. José de Herculânea } \\
\text { (Coxim) }\end{array}$ & * & * & 3.000 & 250 \\
\hline $\begin{array}{l}\text { Sant'Anna } \\
\text { do } \\
\text { Paranaíba }\end{array}$ & Sant'Anna do Paranaíba & 1.793 & 1.547 & $3.24^{* *}$ & 320 \\
\hline Diamantino & $\begin{array}{c}\text { N. S. da Conceição } \\
\text { do Alto Paraguai } \\
\text { (Diamantino) }\end{array}$ & 1.005 & 810 & 1.815 & 270 \\
\hline $\begin{array}{l}\text { Rosário do } \\
\text { Rio Acima }\end{array}$ & $\begin{array}{l}\text { N. S. do Rosário } \\
\text { do Rio Acima }\end{array}$ & 1.651 & 1.612 & 3.263 & 250 \\
\hline Poconé & $\begin{array}{l}\text { N. S. do Rosário } \\
\text { do Poconé }\end{array}$ & 1.520 & 1.409 & 2.929 & 490 \\
\hline $\begin{array}{l}\text { São Luiz de } \\
\text { Cáceres }\end{array}$ & São Luiz de Cáceres & 2.324 & 2.327 & 4.651 & 480 \\
\hline Mato Grosso & $\begin{array}{c}\text { Santíssima Trindade } \\
\text { de Mato Grosso }\end{array}$ & 697 & 801 & 1.498 & 170 \\
\hline$* *$ & $* *$ & 32.417 & 29.904 & 65.321 & 6.110 \\
\hline
\end{tabular}

* Os dados não constam do original.

** Os dados foram transcritos na íntegra.

Fonte: Correa Filho (1919/2002, p.29), dados de 17 ago. 1880; elab.: Pinto, 2013.

A Tabela 1 possibilita visualizar o número de municípios em Mato Grosso, entre os anos de 1870 e 1880 , e seus desdobramentos nas unidades políticas regionais, constituídas por vilas e freguesias. A julgar pelas grandes dimensões territoriais, percebe-se que a população se encontrava distribuída, majoritariamente, em nove municípios, cujas distâncias e dificuldades de acesso estão, notadamente, registradas na História do Estado. À época, a população mato-grossense perfazia a casa dos 60 mil habitantes (Silva, 2011).

Ao tratar de Mato Grosso, os livros didáticos geralmente se atêm a poucos temas, dentre os quais apresentam-se com maior incidência: Guerra do (contra o) Paraguai, presença dos bandeirantes no século XVIII e mineração. ${ }^{12}$ Pensar que já havia, no final do século XIX, movimentação populacional e, 
consequentemente, produtiva nas terras da região central do Brasil, para muitos ainda é mito. A imprensa periódica é advogada dos interesses de divulgação e ampliação da propaganda do território, dentro e fora dos limites territoriais brasileiros.

Capelato (1994) afirma que a imprensa possibilita ao historiador acompanhar o percurso dos homens através dos tempos. A mesma autora afirma que no Brasil, principalmente nas últimas décadas do século XX, a imprensa passou a interessar aos historiadores que reconheceram a sua importância para os estudos históricos, entendendo-a como "fruto ... de um esforço para se repensar problemas, abordagens e objetos da história" (Capelato, 1994, p.20), ao qual se pode acrescentar também a história da educação. Essa autora afirma ainda que

A imprensa, ao invés de espelho da realidade passou a ser concebida como espaço de representação do real, ou melhor, de momentos particulares da realidade. Sua existência é fruto de determinadas práticas sociais de uma época ... a imprensa age no presente e também no futuro, pois seus produtores engendram imagens da sociedade que serão reproduzidas em outras épocas. (Capelato, 1994, p.24)

O exame da imprensa evidenciou outros territórios de circulação de ideias e pessoas, pensando, discutindo e publicando sobre temas diversos, polêmicos ou não, transportando os leitores para situações e contextos em outros momentos históricos. A imprensa em Mato Grosso é pródiga para esse exercício de pesquisa.

O estímulo a pesquisas escolares com base em fontes impressas pode contar com o amparo nas pesquisas em acervos e no exercício cotidiano do paradigma indiciário, sugerido por Carlo Ginzburg (1996). Encontramos em (São Luiz de) Cáceres e Corumbá localidades que compuseram o cenário educacional mato-grossense no período, compartilhando, nas páginas da imprensa, das mesmas preocupações de Cuiabá. As cidades de Corumbá, Cáceres e a capital Cuiabá foram as primeiras que registram a publicação e circulação de uma imprensa periódica com certa regularidade (Tabela 2), destacando-se o fato de serem cidades portuárias, funcionando como entreposto comercial, viabilizando tanto a troca de mercadorias intraestados como a circulação de ideias e notícias entre outros estados da federação e outros países, como registram os correspondentes franceses em O Corumbaense e Echo do Povo. 
Tabela 2 - Jornais examinados entre os anos de 1880 e 1890

\begin{tabular}{l|l|l|c}
\hline \multicolumn{1}{c|}{ Jornal } & Localidade & $\begin{array}{c}\text { Ano (Número de Exemplares } \\
\text { localizados) }\end{array}$ & $\begin{array}{c}\text { Total de } \\
\text { exemplares } \\
\text { consultados }\end{array}$ \\
\hline O Atalaia & Cáceres & $1887(2), 1888(2), 1889(1)$ & 5 \\
\hline O Iniciador & Corumbá & $1877(2) ; 1879(3) ; 1880(3)$ & 8 \\
\hline O Corumbaense & Corumbá & $1881(42) ; 1889(1)$ & 63 \\
\hline A Gazeta & Cuiabá & $1889(39) ; 1890(26)$ & 10 \\
\hline $\begin{array}{l}\text { A Provincia de } \\
\text { Matto Grosso }\end{array}$ & Cuiabá & $1879(1) ; 1881(4) ; 1884(3) ;$ & $1885(1) ; 1889(1)$ \\
\hline A Situação & Cuiabá & $1874(2) ; 1875(1) ; 1886(1)$ & 3 \\
\hline A Tribuna & Cuiabá & $1888(1)$ & 35 \\
\hline O Argos & Cuiabá & $1882(3)$ & 174 \\
\hline \begin{tabular}{l} 
O Expectador \\
\hline
\end{tabular} & Cuiabá & $1884(15) ; 1885(16) ; 1886(4)$ & 4 \\
\hline
\end{tabular}

Fonte: APMT; NDIHR/UFMT (Mato Grosso, 2010); elab.: Pinto, 2013.

Os Anuários Estatísticos Brasileiros do período entre os anos de 1908 e 1912 trazem um extensivo balanço da atividade de imprensa no país, constando mapas e quadros que oferecem ao leitor a possibilidade de entender os locais de funcionamento desses dispositivos de circulação de informação, bem como entender a dimensão política estrutural que ocupavam nas práticas culturais correntes. ${ }^{13}$ Embora com produção pouco expressiva em comparação a São Paulo, Rio de Janeiro e Minas Gerais, Mato Grosso figura entre os estados que contam com atividades editoriais referentes aos impressos de circulação geral.

Em termos de criação, a imprensa em Mato Grosso marca sua história desde a primeira metade do século XIX. Conforme Licurgo Costa e Barros Vidal,

foi em 1840 que, com o Themis Mato-Grossense, publicado em Cuiabá, Mato Grosso teve seu primeiro jornal. Veio depois o "Cuiabano Oficial" e que passou a chamar-se "O Cuiabano", circulando em 1842. E em 1889 tinham vida regular em 
Cuiabá os seguintes jornais: "A Provincia de Mato-Grosso", "A Situação", "A Gazeta”, "A Vespa”,"O Futuro". (Costa; Vidal, 1940, p.53)

Ainda de acordo com esses autores, no período republicano circulavam em Mato Grosso os seguintes jornais: “A Razão, Cáceres - Folha da Serra, Campo Grande - Tribuna, Corumbá - A Folha do Povo, Ponta Porã - A Fronteira, Cáceres - A Mocidade, Ponta Porã - Gazeta do Comércio, Três Lagoas - Mato Grosso, Cuiabá - Gazeta Oficial, Cuiabá - Guaraní, Campo Grande Progressista, Campo Grande - Município, Corumbá” (ibidem, p.183-184).

Nas produções A imprensa oficial em Mato Grosso e na edição comemorativa ilustrada Imprensa Oficial de Mato Grosso: 170 anos de história, Pedro Rocha Jucá (1986; 2009), oferece elementos relevantes para entender a história centenária da imprensa em Mato Grosso, com alto volume de títulos, na sua maioria compostos por jornais particulares - entre os anos de 1848 a 1890 mas que vendiam, mediante a participação em editais públicos, contratos e convênios, espaços nas suas páginas para a publicação dos atos oficiais, enquanto a tipografia do Estado não se estabelecera efetivamente, o que ocorreu a partir de 1890, e que, em certa medida, favorecia a sobrevivência desses periódicos (Jucá, 1986; 2009).

Desse modo, representavam os interesses da sociedade:

o dever de um jornal não é exclusivamente procurar dar o que agradar, é também e principalmente procurar dar o que é util, o que pode produzir proveitosos fructos, ou o que ao menos sirva para despertar o gosto e o amor pelas lettras. A imprensa que procede de modo contrário divorcia-se de seu nobre [?...] a litteratura, que é a expressão do bello. (O Corumbaense, n.60, 16 fev. 1881, p.1)

O ideário de ordenamento com vistas ao progresso encontrava-se estampado nas páginas do jornal:

Do ensino ou do exemplo de desobediência á lei virá o menosprezo á autoridade; da desobediência á autoridade legal virá o menosprezo aos mestres; destes aos paes, e, assim da sociedade passará a anarchia para a família e com a ordem social se subverterá a ordem natural. (Gazetilha, A Situação, n. 458, 28 mar. 1874, p.1)

Cargos públicos, salários, obras completas e excertos da literatura nacional e regional, situações da vida citadina como a chegada e saída dos "vapores", 
pessoas comuns e personalidades políticas e religiosas que desembarcavam nos portos fluviais - esses e outros aspectos da sociedade eram objeto de notícia nas páginas dos jornais mato-grossenses. Em relação à imprensa e aos jornais, propostos aqui como fontes para a discussão, observa-se a possibilidade de viabilizar um levantamento de títulos para a pesquisa documental, tendo em vista que todos possuem sua reprodução preservada pelo Arquivo Histórico de Mato Grosso (APMT) e pelo Núcleo de Documentação Histórica Regional (NDHIR), ambos com sede em Cuiabá, e recentemente contam com digitalização disponível on line, na Hemeroteca da Biblioteca Nacional (BN/RJ). ${ }^{14}$

A Tabela 3 apresenta a sistemática de circulação dos jornais entre os anos de 1880 e 1910, em suas localidades de origem, a qual, ao contrário do que se possa crer, revelou-se profícua e regular:

Tabela 3 - Circulação e comercialização dos exemplares de jornal

\begin{tabular}{|c|c|c|c|c|c|c|}
\hline \multirow{2}{*}{$\begin{array}{l}\text { Jornal/ } \\
\text { Local }\end{array}$} & \multirow{2}{*}{$\begin{array}{l}\text { Valor dos } \\
\text { exemplares } \\
\text { avulsos }^{15}\end{array}$} & \multirow{2}{*}{$\begin{array}{c}\text { Circulação } \\
\text { (Dia da semana) }\end{array}$} & \multicolumn{4}{|c|}{ Valor das assinaturas } \\
\hline & & & Mensal & Trimestral & Semestral & Anual \\
\hline $\begin{array}{l}\text { O Atalaia } \\
\text { (São Luis de } \\
\text { Caceres) }\end{array}$ & * & Domingo & * & * & $7 \$ 000$ & $12 \$ 000$ \\
\hline $\begin{array}{l}\text { O Iniciador } \\
\text { (Corumbá) }\end{array}$ & $\$ 300$ & $\begin{array}{l}\text { Duas vezes por } \\
\text { semana (Quintas } \\
\text { e Domingos) }\end{array}$ & $2 \$ 000$ & $5 \$ 500$ & $10 \$ 000$ & $21 \$ 000$ \\
\hline $\begin{array}{l}\text { O Corum- } \\
\text { baense } \\
\text { (Corumbá) }\end{array}$ & $\$ 160$ & $\begin{array}{l}\text { Uma vez por } \\
\text { semana } \\
\text { (Domingo) }\end{array}$ & $1 \$ 000$ & * & $8 \$ 000^{* *}$ & $14 \$ 000$ \\
\hline $\begin{array}{l}\text { A Gazeta } \\
\text { (Cuiabá) }\end{array}$ & * & Seis vezes por mês & * & $3 \$ 000$ & * & * \\
\hline $\begin{array}{l}\text { A Provincia de } \\
\text { Matto Grosso } \\
\text { (Cuiabá) }\end{array}$ & $\$ 400$ & $\begin{array}{l}\text { Semanal } \\
\text { (Domingo) }\end{array}$ & * & * & $8 \$ 000$ & $15 \$ 000$ \\
\hline $\begin{array}{l}\text { A Situação } \\
\text { (Cuiabá) }\end{array}$ & $\$ 400$ & $\begin{array}{l}\text { Duas vezes por } \\
\text { semana em dias } \\
\text { indeterminados } \\
\text { (Quintas e } \\
\text { Domingos) }\end{array}$ & * & * & $7 \$ 000$ & $12 \$ 000$ \\
\hline
\end{tabular}




\begin{tabular}{|c|c|c|c|c|c|c|}
\hline $\begin{array}{l}\text { A Tribuna } \\
\text { (Cuiabá) }\end{array}$ & $\$ 250$ & Semanal & $1 \$ 000$ & & & \\
\hline $\begin{array}{l}\text { O Argos } \\
\text { (Cuiabá) }\end{array}$ & * & * & * & * & * & * \\
\hline $\begin{array}{l}\text { O Expectador } \\
\text { (Cuiabá) }\end{array}$ & $\$ 300$ & $\begin{array}{l}\text { Semanal } \\
\text { (Quintas e } \\
\text { Domingos) }\end{array}$ & $1 \$ 000$ & * & * & * \\
\hline $\begin{array}{l}\text { Echo do Povo } \\
\text { (Corumbá) }\end{array}$ & * & Sábado & $1 \$ 000$ & * & * & * \\
\hline $\begin{array}{l}\text { Oasis } \\
\text { (Corumbá) }\end{array}$ & * & * & * & * & * & * \\
\hline $\begin{array}{l}\text { O Brazil } \\
\text { (Corumbá) }\end{array}$ & $\$ 500$ & Semanal & * & * & * & * \\
\hline $\begin{array}{l}\text { O Clarim } \\
\text { (Cuiabá) }\end{array}$ & * & * & & $3 \$ 000$ & $6 \$ 000$ & * \\
\hline $\begin{array}{l}\text { O Matto } \\
\text { Grosso } \\
\text { (Cuiabá) }\end{array}$ & * & Semanal & $1 \$ 000$ & * & * & * \\
\hline $\begin{array}{l}\text { O Republicano } \\
\text { (Cuiabá) }\end{array}$ & $\$ 200$ & $\begin{array}{l}\text { Semanal } \\
\text { (Quintas e } \\
\text { Domingos) }\end{array}$ & * & * & $8 \$ 000$ & $15 \$ 000$ \\
\hline Autonomista & $\$ 400$ & $\begin{array}{l}\text { Semanal } \\
\text { (Sábados) }\end{array}$ & * & $5 \$ 000$ & $9 \$ 000$ & $17 \$ 000$ \\
\hline $\begin{array}{l}\text { A Colligação } \\
\text { (Cuiabá) }\end{array}$ & $\$ 500$ & Semanal & * & $3 \$ 000$ & * & $13 \$ 000$ \\
\hline $\begin{array}{l}\text { O Estado } \\
\text { (Cuiabá) }\end{array}$ & $\$ 300$ & Semanal & * & $3 \$ 000$ & $7 \$ 000$ & \\
\hline $\begin{array}{l}\text { O Pharol } \\
\text { (Cuiabá) }\end{array}$ & * & Sábado & $\begin{array}{c}800 \mathrm{a} \\
1 \$ 000^{\star *}\end{array}$ & $2 \$ 500$ & $5 \$ 000$ & $10 \$ 000$ \\
\hline $\begin{array}{l}\text { O Cruzeiro } \\
\text { (Cuiabá) }\end{array}$ & $\$ 300$ & Semanal & $1 \$ 000$ & $3 \$ 000$ & $5 \$ 000$ & $10 \$ 000$ \\
\hline
\end{tabular}

* A informação não consta nas edições examinadas.

${ }^{*}$ Alguns valores divergem, sem justificativa prévia, entre uma edição e outra. Os valores divergem ainda quando é acrescida a tarifa de envio domiciliar (porte) e com relação à circulação no interior e exterior. Considerou-se apenas o valor real. ${ }^{16}$ Fonte: APMT; NDIHR/UFMT (MATO GROSSO, 2010); elab.: Pinto, 2012. 
A fecundidade da iniciativa editorial e a multiplicidade de títulos contrastam, sobretudo, com as condições geográficas e econômicas de Mato Grosso no período, descritas como um "sertão desabitado e inóspito" ou ainda "Sibéria pestilenta”. Ainda que tivessem ciclo de vida efêmero, muitos dos jornais examinados veicularam em suas páginas textos combativos contra uma série de temas, reafirmando a perspectiva das disputas por espaços, veiculação de ideias e legitimação de poder(es).

Nas páginas do jornal $O$ Corumbaense ${ }^{17}$ era possível acompanhar os debates que apontavam as fragilidades do regime imperial em Mato Grosso, anunciando a necessidade, conforme os textos, de mudança pela via da instrução pública. Afinal era necessário, a alguma instância, "advogar os legítimos interesses do paiz, advogando o bem político, promover o progresso moral e material da nação, promovendo o amor pelas lettras e pela instrucção" ( $O$ Corumbaense, 1881, n.58, p.1).

Ao fomentar notas sobre a necessidade de desenvolvimento da estrada de ferro, que daria mais agilidade ao transporte e à circulação de mercadorias, editores e redatores dos jornais colocavam-se como aliados do progresso, atendendo a interesses múltiplos tanto de Mato Grosso quanto de outras localidades que seriam beneficiadas por essa linha de comunicação, a exemplo de São Paulo.

Outro tema explorado nas páginas do periódico e que suscita debates pertinentes quanto ao ensino de história diz respeito à história das mulheres. Embora a questão da feminização do magistério como profissão (ver Almeida, 1996) não estivesse, naquele momento, no centro dos debates ou em evidência, a imprensa permitia visualizar a intensificação da ocupação dos postos de trabalho por mulheres, quando divulgavam os resultados dos concursos para as cadeiras de professores primários, sendo possível perceber, nas décadas seguintes, os embates que o campo profissional anunciava na época. De acordo com os textos correntes, incorporar a mulher ao magistério significaria, de acordo com o exame das notas da imprensa, aumentar o "exército" de braços em prol do desenvolvimento moral da população mato-grossense, opinião que não era partilhada por muitos no final do século XIX.

A exemplo do que ocorria em várias províncias do território nacional, alguns jornais mato-grossenses publicizavam os Atos Oficiais com objetivo de divulgar as realizações do governo, mediante contratos e convênios que serviam 
também para divulgar e dar legitimidade às ações empreendidas em determinados setores. Por exemplo: o volume das publicações referentes à instrução na seção Atos Oficiais é menor do que as iniciativas da Directoria do Arsenal de Guerra e setores judiciais, nas páginas dos semanários A Provincia de MattoGrosso e A Gazeta. Constata-se aí uma hierarquização de temas dignos de nota nos semanários, com base nas distribuições das matérias por edição.

Receber, produzir e divulgar notícias não era a única função assumida pelos jornais do período. A preocupação da seção de apresentação de O Corumbaense, quando justifica aos leitores a existência e manutenção, no seu programa de publicações, de textos literários (dentre outros), consolida a publicação como um bem cultural, não apenas veículo que transcrevia as notas do poder público, ${ }^{18}$ ou dava a conhecer as notícias sobre as práticas do cotidiano.

Nesse aspecto reside, a nosso ver, a precípua função pedagógica da imprensa, em incentivar e valorizar essa prática cultural e os interesses de se constituir uma comunidade de leitores, com vistas ao processo de aprendizagem das letras:

Se todos fossem instruídos, se a illustração estivesse por todos disseminada, é que a imprensa até certo ponto poderia limitar-se ao simples papel de noticiarista, abstendo-se de propagar conhecimentos úteis ao povo, porque então nada adiantaria, seria o caso de dizer - ensina o padre nosso ao vigário; mas justamente pelo facto de ainda haver muita ignorância é que a imprensa tem o imprescindível dever, a menos que se não queira afastar de sua nobre missão, de offerecer aos seus leitores alguma coisa que, além do cunho trivial da novidade, tenha tambem o do bello e o do útil... (Noticiario, O Corumbaense, n.60, 16 fev. 1881, p.1)

Observa-se nesse tipo de posicionamento a função pedagógica da imprensa defendida neste trabalho. Ao ser comparada à "luz do sol" que ilumina os espíritos desprovidos de conhecimento, recupera-se a metáfora das Luzes, inerente ao discurso iluminista, traduzindo a aquisição de conhecimento como elemento de liberdade, consequentemente, de modernidade. Tal função pedagógica pode, igualmente, ser identificada no interior do próprio discurso, na pretensa preocupação em instruir e educar a população: como a educação consiste em um ato intencional, independentemente do direcionamento político que os jornais partilhassem - situação ou oposição -, a pertinência das contribuições para os debates formativos no campo educacional permanecia: 
Se no Brazil lesse-se mais, se tivesse a imprensa outro acolhimento que infelizmente ainda não tem, se pudesse obter pela iniciativa individual vigoroso impulso, com a sua importância e prestigio surgirião as escolas se preparariam as multidões, porque o gosto para o estudo ella se incumbiria de despertar-lhes. $(O$ Corumbaense, n.65, 5 mar. 1881, p.1)

A imprensa, em alguns momentos, arregimenta a responsabilidade e o interesse de conclamar o poder público a mobilizar-se em prol da implantação e organização do aparelho escolar no Estado. Pode-se afirmar o interesse capital dos responsáveis por aqueles veículos em fomentar processos de ensino de leitura visando, entre outros motivos, a ampliação do público leitor (potenciais assinantes) de suas folhas.

\section{CONSIDERAÇÕES FINAIS}

O ensino de história permite ousar. Permite a interface de seus conteúdos com a diversidade de documentação produzida sobre o período em ensino, fomentando comparações, conexões e relações que favorecem a compreensão diacrônica dos acontecimentos históricos, sem a pretensão de tomá-los como expressão de verdade absoluta, mas sim como fatos históricos, que tiveram seu registro efetivado a partir de um determinado viés, teórico ou temático.

Ao discutir uma das tarefas do historiador, que a nosso ver perpassa a tarefa do professor de História, Darnton assevera:

Ao historiador, portanto, deveria ser possível descobrir a dimensão social do pensamento e extrair a significação de documentos, passando do texto ao contexto e voltando ao primeiro, até abrir caminho através de um universo mental estranho. Esse tipo de História Cultural pertence às ciências interpretativas ... Então, os historiadores deveriam ser capazes de perceber como as culturas formulam maneiras de pensar, mesmo no caso dos grandes pensadores. Um poeta ou um filósofo pode levar a linguagem aos seus limites mas, a certa altura, vai deparar-se com a estrutura externa da significação. (Darnton, 1986, p.XVII-XVIII)

Imbuídos da responsabilidade em formular maneiras de pensar através de "um universo mental estranho", como assevera Darnton, buscou-se demonstrar as potencialidades do uso da imprensa periódica como material de 
apoio para o ensino de história, sobretudo o ensino da história da região em que circularam os periódicos em exame, conferindo possibilidades de analise e interpretações no que concerne ao processo histórico de criação e fundação das cidades, relações comerciais e culturais, referências nacionais e estrangeiras adotadas como modelos para a formatação de costumes dentre outros elementos potenciais ao ensino de história regional.

Os jornais considerados "de época", por estarem situados em uma cronologia distinta e distante do tempo presente, revelaram temas e abordagens distintos de outras tipologias documentais pela sua própria característica de formatação, autoria e direcionamento dos textos que apresentam, dando a conhecer: textos de opinião, legislação, anúncios e propagandas do comércio local, anedotas e relatos de insatisfações da população com situações do contexto local.

Para o ensino de história, potencializam-se todas essas tipologias textuais em direção a uma reescrita da história das localidades mencionadas, não em uma perspectiva do rigor acadêmico, mas estimulando, inicialmente, a curiosidade nata em crianças e adolescentes, por meio da pesquisa em acervos e locais de preservação física do patrimônio local, em um trabalho de reconstrução histórica, com base formativa.

Considera-se oportuno, a título de conclusão, retomar as palavras de Marco Morel em relação à importância dos dispositivos de imprensa, externados neste trabalho como fontes de apoio significativo para o ensino de momentos históricos:

Os jornais do período inicial constituíram-se, em alguns casos, através das várias redes de sociabilidade, dentro das condições da época, formadas no Brasil recém-independente que buscava se constituir em nação. Não se deve negligenciar dentro desses laços que se articularam (criavam, mantinham ou refaziam), com densidades desiguais, uma forma de associação bastante específica em suas características, embora articulada com as demais: as redes de sociabilidade pela imprensa periódica. Essa pode ser considerada um palpável agente histórico, com sua materialidade no papel impresso e efetiva força simbólica das palavras que fazia circular, bem como dos agentes que a produziam e dos leitores/ouvintes que de alguma forma eram receptores e também retransmissores de seus conteúdos. (Morel, 2008, p.41) 
Para o trabalho efetivo em sala de aula consideramos oportuna a realização de visitas aos acervos e arquivos de preservação e guarda de documentação, ou, na impossibilidade da vinda, o convite de profissionais desses setores para proferirem palestras e oficinas temáticas que demonstrem a viabilidade do trabalho com o material que possuem. Ao lado do conhecimento desses lugares de preservação da memória histórica local e nacional, faz-se necessária a seleção da documentação que se pretende utilizar associada ao componente curricular a ser ensinado, entendendo que as formas de reproduzir e veicular a documentação devem estar alicerçadas a uma proposta metodológica para seu efetivo exercício.

O trabalho do professor, diante dessa premissa, ultrapassa a preparação das suas aulas a partir do material disponível e “em mãos”, como por exemplo os livros didáticos regulamentados pelas escolhas trienais do Programa Nacional do Livro Didático (PNLD), demandando investimento potencial em estudo e conhecimento acerca da área de sua atuação local. A discussão realizada por Jürgen Schriewer (1995) referente aos modelos educacionais em circulação e sistemas de referência, cujas formas de uso regional são dadas a partir das formas de apropriação e condições possíveis para a sua implementação e desenvolvimento do país, auxilia no entendimento sobre como compreender o regional sem preterir o contexto nacional.

Na perspectiva da aquisição e desenvolvimento das habilidades cognitivas, a abstração e a ação de projetar-se para um tempo distinto ao presente, intermediados pelo ensino da História da sua localidade, funcionam como condição significativa para o desenvolvimento da sensação de pertencimento à realidade local. Nesse sentido, partilhamos da preocupação de Lucybeth Camargo de Arruda, quando, em relação ao ensino da história indígena a partir de documentos, afirma:

É importante situarmos os alunos no processo histórico, demonstrando numa prática vivenciada que as histórias dos lugares e dos atores sociais estão confirmadas a partir de um contexto sociopolítico, econômico e cultural que deve ser levado em conta; lembrando que a história é composta de continuidades e descontinuidades e que, portanto, só é possível entendê-las quando contextualizadas. Desse modo, estimulamos os alunos a compreender e valorizar não uma história dada e pronta e sim uma história construída e composta por atores sociais que deixam de ser o "outro" distante... (Arruda, 2007, p.95) 
Por fim, a leitura e o exame de jornais "de época" tornam possível saber, em certa medida, o que estava acontecendo em outros lugares e momentos do Império com base na escrita de autores que não necessariamente estão comprometidos com a produção do conhecimento formal ou oficial e traduzem certo modo de ver as questões do cotidiano. Pessoas comuns, de posse de um instrumento de registro de opiniões, contribuíram para instituir representações acerca dos acontecimentos políticos e sociais de Mato Grosso.

Em suma, potencializar o ensino de história a partir de registros dessa natureza consiste em desmistificar a ideia de que a história é construída apenas por grandes homens e demarcada por grandes acontecimentos, como registram as datas cívicas. A história é produzida diariamente e registrada a partir dos dispositivos disponíveis em cada período, os quais guardam marcas de poder e manipulação mas, ainda assim, não deixam de ser fontes potenciais para entender aspectos da sociedade em que se inseriram. Assim, editores, autores, articulistas, impressores e todos aqueles que estiveram envolvidos com a produção e circulação de jornais tornaram-se personagens da história, sendo também sujeitos das condições impostas por seu tempo e lugar.

\section{REFERÊNCIAS}

\section{FONTES}

A Colligação. Edições de 1900 a 1910. Campo Grande. Arquivo Público do Estado de Mato Grosso do Sul. Campo Grande: APE-MS, 2010.

A Gazeta. Edições de 1880 a 1890. Cuiabá. Arquivo Público do Estado de Mato Grosso. Cuiabá: APMT, 2010.

A Provincia de Matto Grosso. Edições de 1880 a 1890. Arquivo Público do Estado de Mato Grosso. Cuiabá: APMT, 2010.

A Situação. Edições de 1880 a 1890. Cuiabá. Arquivo Público do Estado de Mato Grosso. Cuiabá: APMT, 2010.

A Tribuna. Edições de 1880 a 1890. Corumbá. Instituto Histórico e Geográfico de Mato Grosso. Cuiabá: IHGMT, 2010.

Echo do Povo. Edições de 1890 a 1910. Corumbá. Instituto Histórico e Geográfico de Mato Grosso. Cuiabá: IHGMT, 2010.

Oasis. Edições de 1890 a 1900. Corumbá. Instituto Histórico e Geográfico de Mato Grosso. Cuiabá: IHGMT, 2010. 
O Argos. Edições de 1880 a 1890. Cuiabá. Arquivo Público do Estado de Mato Grosso. Cuiabá: APMT, 2010.

O Atalaia. Edições de 1880 a 1890. Cáceres. Arquivo Público do Estado de Mato Grosso. Cuiabá: APMT, 2010.

O Autonomista. Edições de 1900 a 1910. Corumbá. Arquivo Público do Estado de Mato Grosso do Sul. Campo Grande: APE-MS, 2011.

O Brazil. Edições de 1900 a 1910. Corumbá. Arquivo Público do Estado de Mato Grosso (Cuiabá), 2010.

O Clarim. Edições de 1890 a 1900. Cuiabá. Instituto Histórico Geográfico de Mato Grosso (Cuiabá) 2010.

O Corumbaense. Edições de 1880 a 1890. Cuiabá. Arquivo Público do Estado de Mato Grosso. Cuiabá: APMT, 2010.

O Cruzeiro. Edições de 1900 a 1910. Cuiabá. Arquivo Público do Estado de Mato Grosso. Cuiabá: APMT, 2010.

O Estado. Edições de 1900 a 1910. Cuiabá. Arquivo Público do Estado de Mato Grosso. Cuiabá: APMT, 2010.

O Expectador. Edições de 1880 a 1890. Corumbá. Arquivo Público do Estado de Mato Grosso. Cuiabá: APMT, 2010.

O Iniciador. Edições de 1880 a 1890. Cuiabá. Arquivo Público do Estado de Mato Grosso. Cuiabá: APMT, 2010.

O Matto Grosso. Edições de 1890 a 1910. Cuiabá. Arquivo Público do Estado de Mato Grosso. Cuiabá: APMT, 2010.

O Pharol. Edições de 1900 a 1910. Cuiabá. Arquivo Público do Estado de Mato Grosso. Cuiabá: APMT, 2010.

Republicano. Edições de 1890 a 1910. Cuiabá. 2010. Arquivo Público do Estado de Mato Grosso. Cuiabá: APMT, 2010; Arquivo Público do Estado de Mato Grosso do Sul. Campo Grande: APE-MS, 2011.

\section{BIBLIOGRAFIA}

ALMEIDA, Jane Soares. Paixão pelo possível. São Paulo: Ed. Unesp, 1996.

ALVES, Gilberto Luiz. Educação e História em Mato Grosso (1719-1864). 2.ed. rev. e ilustr. Campo Grande: Ed. UFMS, 1996.

ARRUDA, Lucybeth Camargo de. Nos limites da Fronteira Oeste: uma história da atração nos Postos indígenas do SPI em Mato Grosso. In: JESUS, Nauk Maria de; CEREZER, Osvaldo Mariotto; RIBEIRO, Renilson Rosa. (Org.) Ensino de história: trajetórias em movimento. Cáceres, MT: Ed. Unemat, 2007. p.85-95. 
BITTENCOURT, Circe Maria Fernandes. Ensino de História: fundamentos e métodos. São Paulo: Cortez, 2004.

. Livro didático e conhecimento histórico: uma história do saber escolar. Tese (Doutorado) - FFLCH, Universidade de São Paulo. São Paulo, 1993.

BOURDIEU, Pierre. A identidade e a representação: elementos para uma reflexão crítica sobre a ideia de região. In: O poder simbólico. Rio de Janeiro: Bertrand Brasil, 2002. p.106-132.

CHARTIER, Roger. A história cultural: entre práticas e representações. Rio de Janeiro: Difel; Bertrand Brasil, 1988. (Coleção Memória e Sociedade).

CHERVEL, Andre. História das disciplinas escolares: reflexões sobre um campo de pesquisa. Teoria \& Educação, Porto Alegre, n.2, 1990.

CORREA, Valmir Batista. Coronéis e Bandidos em Mato Grosso. (1.ed. 1995). 2.ed. Campo Grande: Ed. UFMS, 2006.

CORREA FILHO, Virgilio Alves. Questões de ensino: monografias cuiabanas. v.1. São Paulo: Monteiro Lobato, 1925.

. Monografias Cuiabanas: questões de ensino. Cuiabá: Instituto Histórico e Geográfico de Mato Grosso, 2002. (Publicações avulsas, 59).

COSTA, Angela Marques da; SCHWARCZ, Lilia Moritz; MELO e SOUZA, Laura de. Finais do século são bons para pensar. Esse é o momento de apostas. In: COSTA, A. M. da (Coord.) 1840-1914: No tempo das certezas. São Paulo: Companhia das Letras, 2000. (Coleção Virando Século).

COSTA, Licurgo; VIDAL, Barros. História e evolução da imprensa brasileira. Rio de Janeiro, 1940. (Editado pela comissão organizadora da representação brasileira à exposição dos centenários de Portugal). Consultado no CPDOC da FGV, jan. 2011.

DARNTON, Robert. O grande massacre de gatos e outros episódios da história cultural francesa. Trad. Sonia Coutinho. Rio de Janeiro: Graal, 1986.

DEBONA, Jackson James. Entre o regional e o nacional: Mato Grosso do Sul nos livros didáticos de história (PNLD/2011). 2014. (mimeo.)

FARIA, Maria Alice. Como usar o jornal em sala de aula. 8.ed. São Paulo: Contexto, 2003.

FRONZA, Marcelo. A intersubjetividade e a verdade na aprendizagem histórica de jovens estudantes a partir das histórias em quadrinhos. Tese (Doutorado em História) - Universidade Federal do Paraná. Curitiba, 2012.

GIACOMONI, Marcello Paniz; PEREIRA, Nilton Mullet (Org.) Jogos e ensino de história. Porto Alegre: Evangraf, 2013.

GINZBURG, Carlo. O queijo e os vermes. São Paulo: Companhia das Letras, 1996. 
GONÇALVES, Marcia de Almeida. História Local: o reconhecimento da identidade pelo caminho da insignificância. In: MONTEIRO et al., 2007, cit., p.175-185.

HOBSBAWM, Eric. Não basta a história de identidade. In: Sobre história. São Paulo: Companhia das Letras, 1998. p.281-308.

JUCÁ, Pedro Rocha. Imprensa oficial de Mato Grosso. Cuiabá: Imprensa Oficial do Estado de Mato Grosso, 1986.

Imprensa oficial de Mato Grosso: 170 anos de história. (com ilustrações). Cuiabá: Aroe, 2009. Disponível em: www.iomat.mt.gov.br; Acesso em: 10 maio 2010.

LE GOFF, Jacques. A História Nova. 5.ed. São Paulo: Martins Fontes, 2005. p.1-90.

Prefácio. In: BLOCH, Marc. Apologia da História ou o ofício de historiador. Rio de Janeiro: Jorge Zahar, 2001. p.15-38.

LEITE, Gervásio. Um século de instrução pública: história do ensino primário em Mato Grosso. Goiânia: Ed. Rio Bonito, 1970.

MACIEL, Laura. História regional e ensino: Diálogos com professores e alunos. In: RIBEIRO, Renilson Rosa; LIMA, Alexandra; FRONZA, Marcelo. Dossiê História Regional: historiografia e ensino de História. Revista Eletrônica Documento/Monumento, v.9, n.1, p.79-93, out. 2013. Disponível em: www.ufmt.br/ndihr/revista; Acesso em: 7 out. 2014.

MONTEIRO, Ana Maria; GASPARELLO, Arlette Medeiros; MAGALHÃES, Marcelo de Souza (Org.) Ensino de História: sujeitos, saberes e práticas. Rio de Janeiro: Mauad X; Faperj, 2007.

MOREL, Marco. Os primeiros passos da palavra impressa. In: MARTINS, Ana Luiza; LUCA, Tania Regina de. (Org.) História da Imprensa no Brasil. São Paulo: Contexto, 2008. p.22-43.

NADAF, Yasmin Jamil. Rodapé das miscelâneas: o folhetim nos jornais de Mato Grosso. Rio de Janeiro: Sette Letras, 2002.

Sob o signo de uma flor. Rio e Janeiro: Sette Letras, 1993.

PINTO, Adriana Aparecida. Nas páginas da imprensa: a instrução/educação nos jornais em Mato Grosso: 1880-1910 Tese (Doutorado em Educação Escolar) - Universidade Estadual Paulista, Faculdade de Ciências e Letras. Araraquara, 2013.

QUEIROZ, Paulo Roberto Cimó. A historiografia sul-mato-grossense, 1968-2010: notas para um balanço. In: GLEZER, Raquel. Do passado para o futuro: edição comemorativa dos 50 anos da Anpuh. São Paulo: Contexto, 2011. p.167-185.

RIBEIRO, Renilson Rosa; LIMA, Alexandra; FRONZA, Marcelo. Dossiê História Regional: historiografia e ensino de História. Revista Eletrônica Documento/Monumento, v.9, n.1, out. 2013. Disponível em: www.ufmt.br/ndihr/revista; Acesso em: 7 out. 2014. 
SCHELBAUER Analete Regina; ARAUJO, José Carlos Souza (Org.) História da Educação pela imprensa. Campinas, SP: Alínea, 2007.

SCHMIDT, Maria Auxiliadora; BARCA, Isabel; MARTINS, Estevão de Rezende. Jörn Rüsen e o ensino de história. Curitiba: Ed. UFPR, 2011.

SCHRIEWER, Jürgen. Sistema Mundial e Inter-relacionamento de redes: a internacionalização da educação e o papel da pesquisa comparativa. Revista Brasileira de Estudos Pedagógicos, Brasília, v.76, n.182-183, jan.-ago. 1995.

SILVA, Cristiani Bereta da; ZAMBONI, Ernesta (Org.) Ensino de História, memória e culturas. 1.ed. Curitiba: CRV, 2013.

SILVA, Tereza de Pazos da. Reformas Educacionais em Mato Grosso: os diferentes sujeitos e a constituição de diferentes sentidos ao processo de instruir/educar. Tese (Doutorado em Educação Escolar) - Faculdade de Ciências e Letras, Universidade Estadual Paulista. Araraquara, 2011.

SIQUEIRA, Elizabeth Madureira. História de Mato Grosso: da ancestralidade aos dias atuais. Cuiabá: Entrelinhas, 2002.

SIQUEIRA, Elizabeth Madureira; COSTA, Lourença Alves da; CARVALHO, Cathia Maria Coelho. O processo Histórico de Mato Grosso. Cuiabá: Ed. UFMT; Guaicurus, 1990.

TARDIF, Maurice. Saberes docentes e formação profissional. Petrópolis, RJ: Vozes, 2002.

ZORZATO, Osvaldo. Alicerces da identidade mato-grossense. Revista do Instituto Histórico Geográfico Brasileiro, Rio de Janeiro, ano 161, n.408, p.419-437, jul.-set. 2000.

\section{NOTAS}

${ }^{1} \mathrm{O}$ presente artigo tem como base um estudo realizado sobre a imprensa periódica em Mato Grosso entre os anos de 1880-1910, com enfoque nas notas produzidas sobre instrução e educação no período em exame. Ver: PINTO, 2013.

${ }^{2}$ Várias obras possibilitam uma descrição das origens do território de Mato Grosso, contudo optamos por esta, de Manoel Rodrigues Ferreira: "Em 1719, os bandeirantes de São Paulo descobrem ouro na região de Cuiabá e que fica denominada 'Minas do Cuiabá' ... Minas do Cuiabá e Minas do Mato Grosso constituíam dois distritos auríferos separados. As Minas do Cuiabá tinham como centro a vila de Cuiabá, situada na margem direita do rio de mesmo nome. As Minas do Mato Grosso situavam-se entre a Chapada dos Parecis e o Rio Guaporé, tendo três arraiais principais: São Francisco Xavier, Santana e Pilar ... Em Lisboa, o Rei D. João V resolve, em uma visita daquelas circunstâncias, criar uma nova unidade administrativa no Estado do Brasil, que englobasse aqueles dois distritos auríferos denominados Cuiabá e Mato Grosso ... A capital da Capitania de Mato Grosso teria de ser 
uma cidade cientificamente planejada, segundo modernas concepções urbanísticas da época. Deveria ser localizada no melhor lugar do distrito das Minas do Mato Grosso. Deveria ser formosa, constituir um fulgurante marco da civilização naquele dilatado sertão do interior do Estado do Brasil" (FERREIRA, 1960, p.35-36).

${ }^{3}$ Para conhecer e acompanhar os debates vale conferir, sobre a historiografia mato-grossense, SIQUEIRA, 2002; SIQUEIRA et al., 1990; CORREA FILHO, 2002; 1925.

${ }^{4}$ Sobre o tema ver DEBONA, 2014.

${ }^{5}$ Sobre experiências e pesquisas realizadas sobre história local ver: Gonçalves, 2007.

${ }^{6}$ Eudes Fernando Leite já assinalava a necessidade de produção de material didático e paradidático para o ensino de História Regional desde 2010. Sobre o tema ver: QUEIROZ, 2011.

${ }^{7}$ Atualmente contamos com os seguintes materiais para consulta e subsídio didático para o ensino de História Regional: SIQUEIRA, Elizabeth Madureira. História de Mato Grosso; VALDEZ, Diane; AMARAL, Mirian Bianca do. História de Mato Grosso do Sul (2011); GRESSLER, Lori Alice; VASCONCELOS, Luiza Mello; SOUZA, Zelia Peres de. História de Mato Grosso do Sul (2008), todos aprovados no PNLD 2014 para distribuição em 2015. Registre-se que esses materiais são as fontes de consultas mais conhecidas e acessíveis.

${ }^{8}$ Para entender a fundamentação desse modo de pensar ver: BOURDIEU, 2002; HOBSBAWM, 1998.

${ }^{9}$ A transcrição das fontes (jornais) foi mantida conforme os originais.

${ }^{10}$ Sobre a atualidade das pesquisas em ensino de história em Mato Grosso vale consultar: Dossiê História Regional: historiografia e ensino de História. Revista Eletrônica Documento/Monumento, v.9, n.1, out. 2013. Disponível em: www.ufmt.br/ndihr/revista.

${ }^{11}$ Criada em 1995 em Curitiba, a Editora Base, como consta em sua carta programa, dedica-se a produzir materiais didáticos em conformidade com os Programas Governamentais. Conferir: www.editorabase.com.br/?system $=$ produtos\&action $=$ colecoes \&proc id=22\&prca_id=2\&pros_id=2; Acesso em: 9 out. 2014.

${ }^{12}$ Essa discussão encontra-se em Debona, 2014.

${ }^{13}$ Data de 20 de dezembro de 1907 a legislação que obriga a remessa à Biblioteca Nacional de, no mínimo, um exemplar de todas as obras impressas produzidas e postas em circulação no Brasil (Decreto no 1825). Sobre o tema vale ainda consultar o texto "A legislação de imprensa desde o Brasil Colônia até a época de Vargas", parte integrante do Anuário da Imprensa Brasileira, disponível no CPDOC/FGV, consultado em jan. 2011. Consta do documento a relação de nomes de cidadãos mato-grossenses cadastrados e registrados como jornalistas. Ver: Anuário da Imprensa Brasileira, 1939, p.65 (Ed. FGV, 2011).

${ }^{14}$ Consultar visita virtual: http://www.bn.br.

${ }^{15}$ Não obtivemos, no exame da bibliografia, elementos para discutir esse aspecto, mas alguns questionamentos podem ser realizados nesse sentido, tendo em vista que os jornais 
são produzidos para serem lidos. Ainda que pesem todos os problemas relativos às formas de aquisição da leitura no território mato-grossense, os próprios editores chegam a publicar críticas com relação aos leitores fortuitos e oportunistas que "ouvem" o jornal. Se o interesse era divulgar, as técnicas de impressão não dispunham de recursos muito variados para se apresentarem tipograficamente muito distintos uns dos outros - quais os motivos que levavam à prática de valores tão diversos? Os gastos com a produção, impressão e distribuição devem ser levados em consideração, mas ainda assim persiste a indagação. Elementos para a investigação de uma história da educação e da leitura se avizinham a esses questionamentos.

${ }^{16}$ Apenas a título de informação, seguem os preços de alguns itens, utilizados no cotidiano mato-grossense como gêneros de primeira necessidade, na tentativa de entender, em termos de valores, quanto se despendia para comprar um jornal: "Sabão arroba $6 \$ 800$; barra 360rs; Erva doce Kilo 1\$400; Manteiga $1 \$ 500$; Bacalhao 500rs; Sal saco 5\$800. Na loja do Nho Veto" (Proposta para o Rancho, A Gazeta, 26 nov. 1889, p.4).

${ }^{17}$ O Corumbaense: "órgão dos interesses do commercio, da lavoura e da instrucção popular, litterario e noticioso”, circulava em Corumbá duas vezes por semana, não sendo possível identificar nos números examinados o dia exato, mas a julgar pelas publicações observadas, poderia ser entre terças e quintas-feiras, pois, em geral, os jornais com apenas duas edições semanais saíam aos domingos. Era de propriedade de Antonio Malheiros e André Troyano de Rocha Passos, apresentando em algumas edições a epígrafe "propriedade de sociedade anonyma”, mas, segundo João Carlos Souza, era financiado pelos comerciantes locais. As edições localizadas a partir do número 58, durante o ano de 1880-1881, guardam características bastante específicas àquelas localizadas a partir de 1889, cujo Diretor foi Firmo José Rodrigues, e a sua apresentação é alterada para O Corumbaense: periódico político e noticioso.

${ }^{18}$ O estudo de Yasmin Nadaf (2002) evidencia a preocupação com o componente literário nas páginas dos jornais mato-grossenses.

Artigo recebido em 14 de agosto de 2014. Aprovado em 28 de outubro de 2014. 